\title{
Obesity Alters Balance and Movement Control
}

\author{
Normand Teasdale • Martin Simoneau • Philippe Corbeil • \\ Grant Handrigan • Angelo Tremblay • Olivier Hue
}

Published online: 18 June 2013

(C) Springer Science+Business Media New York 2013
Keywords Balance $\cdot$ Obesity $\cdot$ Strength $\cdot$ Training $\cdot$ Postural constraints $\cdot$ Plantar mechanoreceptors $\cdot$ Movement control

\section{Introduction}

The burden of obesity is widely known for its impact on health from a physiological aspect. For instance, there are associations with diseases such as type 2 diabetes, coronary heart disease, pulmonary dysfunction, musculoskeletal disease, cancer and many others. The negative consequences of obesity, however, extend well beyond these physiological aspects. For instance, when compared to healthy-weight people, the chances of suffering from a fall-related injury requiring medical treatments are 15 to $79 \%$ higher for overweight individuals [1], and injuries such as sprains, strains, and dislocations are more often due to falls [2]. In a study of more than 7000 workers over a period of two years, Pollack and Cheskin [3] also observed an increased rate of knee, hand, wrist, and finger injuries among morbidly obese workers (BMI $>40 \mathrm{~kg} / \mathrm{m} 2$ ) when compared to healthy weight workers. Similar observations were made with a large sample of adult Canadian workers [4]. Finally, a recent study revealed that the use of a weight control program in the workplace could reduce the frequency of several work-related injuries among obese individuals [5]. Altogether, these epidemiological studies support the suggestion of a strong link between obesity and the frequency of work-related injuries involving a fall or limbs injuries.

This manuscript presents evidence showing that obesity modifies how fundamental daily activities such as standing [6] or simply grasping or pointing to an object $[7,8]$ are performed. A main hypothesis for suggesting that balance control is perturbed in obese individuals is that plantar mechanoreceptors may be less receptive due to the continuous pressure of supporting a large mass. This decreased sensory information may explain why obese individuals are less stable. Preliminary data supporting this hypothesis are presented. 
Overall, this review makes the case that losing weight may be the only solution for improving balance control. This has important clinical implications.

\section{Obesity and Balance Control}

External and internal forces acting on the erect body create destabilizing events yielding postural oscillations. The postural control system regulates these oscillations by maintaining the vertical alignment of the body segments. When a person stands on a force platform, the point of application of the ground reaction forces under the feet (center of foot pressure, $\mathrm{CoP}$ ) is the outcome of the inertial forces of the body and the restoring equilibrium forces of the postural control system. It is generally accepted that the mean speed of the CoP displacements is an indicator of postural stability with a greater speed indicating a decrease in postural stability [9-11]. In the past few years, several studies have shown the existence of a close relationship between obesity and postural stability with obesity leading to a decreased stability.

In particular, Hue et al. [12] revealed a linear relationship between weight and the speed of the CoP displacement for male subjects having a BMI between 17.4 and $63.8 \mathrm{~kg} / \mathrm{m}^{2}$ of 25-61 years old; the heaviest participants showing the greatest speed of the CoP. In this latter study, the results of a multiple regression demonstrated that over $55 \%$ of the variance observed for the average speed of the $\mathrm{CoP}$ (with or without vision) was explained by body weight. Age contributed very little to the prediction of postural oscillations (less than $10 \%$ of the variance explained for all evaluated regression models). This general detrimental effect of obesity on balance control also has been observed for children [13, 14], pre-pubertal boys [15], HIV seropositive patients [16], young and athletic individuals with a BMI corresponding to that of obese individuals [17•], genetically obese patients [18], and older women [19]. To our knowledge, there is a single exception to this general result [20], and it has been questioned [21].

Perhaps, one of the most significant demonstrations that obesity perturbs balance control is that of Teasdale et al. [6]. In this study, weight loss was induced in obese (hypocaloric diet) and morbid obese individuals (bariatric surgery). These subjects were tested before and after weight loss. A control group also was tested twice at 6-month intervals. The key result is that weight loss lead to a decrease in the range and speed of the CoP. The magnitude of the decrease was directly related to the amount of weight that was lost. The control group did not show any change. These results are important since they show that being overweight represents an important postural constraint that negatively affects postural stability, and that weight loss has a direct effect on reducing postural oscillations. Obesity could represent an important risk factor for falls; a factor that has been given, up to now, little attention.

\section{Posture, Movement, and Obesity}

For the vast majority of our daily activities, balance control assists goal-directed movements and precedes a dynamic activity (for instance, when reaching for an object from an upright posture). Voluntary movements create forces upon the whole body and the environment. These forces need to be controlled to ensure stability and to accurately reach and efficiently grasp an object. To counteract these forces, stabilizing motor commands (i.e., anticipatory postural adjustments) occur prior to the limb movements [22-26]. Therefore, when one points at a target or grasps an object, a less stable initial posture could add a constraint and limit the performance. This hypothesis was tested first with healthy weight participants [27] using a Fitts' type protocol [28], in which subjects pointed as quickly as possible to a target of various sizes located in front of them. In this type of protocol, the time required to execute the pointing movement is directly associated with the target's size. More precisely, movement time generally increases linearly with the index of difficulty of the movement $(\mathrm{ID}=\log 2[2 \mathrm{~A} / \mathrm{L}]$, where $\mathrm{A}$ is the amplitude of the movement and L, the target's size). Two postural conditions were used; sitting or standing upright. The location of the starting point and targets' relative to the body's position (and eyes) were the same for the two postural conditions. The hypothesis was that standing upright, because it adds a postural constraint, should lead to a greater slope for the movement time-ID relationship. Results showed that movement time increased with an increasing ID for both postural conditions. However, the increase in movement time was greater when movements were executed in the standing position. This observation was more pronounced for small targets and was primarily caused by an increase in the duration of the deceleration phase of the pointing movement. Overall, these results confirm that the control of balance represents a constraint for the execution of accurate upper limb movements [27].

If obesity adds a postural constraint, then the slope of the movement time-ID relationship should also be greater for obese individuals than for individuals with a healthy weight. Berrigan et al. [7] tested this hypothesis by comparing the movement time-ID relationship of obese individuals (BMI between 30 and $40 \mathrm{~kg} / \mathrm{m}^{2}$ ) and healthy-weight individuals (BMI $<25 \mathrm{~kg} / \mathrm{m}^{2}$ ) when they pointed to targets from a standing position. In accordance to Fitts' law, the movement times of both groups increased with a decrease of the target's size (that is, with an increasing difficulty). For obese subjects, however, the more difficult conditions (i.e., smaller target sizes) resulted in a greater increase in movement time. Moreover, obese subjects showed greater amplitude and 
speed of body oscillations confirming that obesity increases body oscillations and reduces the performance of pointing movements performed while standing. A subsequent study demonstrated that a weight loss program improves the speedaccuracy performance of pointing movements in the upright posture [29]. No change in performance was observed when movements were executed while sitting suggesting the improvement in performance was not a result of a local inertial factor (that is, decrease mass of the upper limbs following weight loss), but rather of a global inertial factor affecting the control of balance.

These results emphasize that being overweight has a negative effect on the control of balance, and on the speed-accuracy performance of upper-limb movements executed in a standing posture. A similar observation was made by D'Hondt et al. [8] in a study with children aged 6 to 10 years. These authors compared the performance of children having a healthy weight to that of obese children in a fine manipulation and manual coordination task (Purdue Pegboard Task). The task simply consists of picking up a small metal peg with one hand, grasping it with the contralateral hand and placing it in a peg hole. The performance for this task is measured by the number of correctly placed peg in a given period of time. The task was performed in a standing position on a normal support surface or when both feet were positioned on a $4.5 \mathrm{~cm}$ large beam, thus challenging balance control. The performance of all children was reduced (fewer pegs placed correctly) when standing on the narrow base of support; obese children, however, placed far fewer pegs correctly compared to children with a healthy weight when they stood on the beam. D'Hondt et al. [30] also observed that differences in gross motor coordination between obese and normal-weight children widens through a 2-year interval. These observations confirm the work of Berrigan et al. [7, 29] with adult obese individuals; when the control of balance is incidental to the execution of upper limb movements, obesity negatively affects the control of balance and reduces the efficiency of upper limb movements.

\section{Could an Increase in the Strength of the Lower Limbs, Achieved through Training, be a Solution to the Decreased Postural Stability of Obese Individuals?}

To ensure balance, the motor commands directed toward the postural muscles must compensate the system's weight and its deviations relative to a neutral position. An increase in the body mass is necessarily coupled to an increase in the amplitude of the motor commands sent to these muscles; this introduces more variability in the motor commands controlling body oscillations. This has been shown by Li and Aruin [31] in a study where adding a mass simulating an excess weight of 20 and $40 \%$ of the body mass resulted into an increase in the activity of the postural muscles as well as an increase in the amplitude of the CoP displacements. The work of Corbeil et al. [32] also suggests that, for obese individuals, an increased ankle torque is necessary to ensure stability after small perturbations. Mathematical simulations demonstrated the ankle torques were even greater when the position of the center of mass was more off-centered from the ankle joint, exceeding in certain specific conditions, the maximal moment of force that an individual can generate while standing. These results suggest that a larger weight could be a potential risk for falls.

Several authors have proposed that a training program could mitigate the negative effects of obesity on balance control [33-35]. For example, Maffiuletti et al. [34] showed that a weight-loss program combined with a six sessions balance training program reduced trunk oscillations and enhanced the time of balance maintenance for tests performed on a mobile platform. An implicit hypothesis underlying this suggestion is that the decreased postural stability of the obese individuals is associated with reduced physical activity, which is often seen among these individuals [e.g., 36]. Therefore, the hypothesis presented by these authors $[33,34,37]$ is that a regular physical activity program would allow a better weight control and also improve postural stability. In these studies, however, weight loss and physical activity are two factors that cannot be dissociated. Recent studies performed by our team provide important information with that regard. Firstly, weight loss, when not related to a regular physical activity program, leads to a decrease in strength. As an example, Hue et al. [38] showed that, for obese subjects, a hypocaloric diet led to a weight loss of $11.8 \mathrm{~kg}(11.1 \%$ of the initial weight $)$ and to a $10.1 \%$ decrease of the lower limbs' maximal force. For morbidly obese subjects who received a bariatric surgery, the decrease in strength was $33.5 \%$ (weight loss of $70.8 \mathrm{~kg}$ corresponding to a loss of $46.3 \%$ of the initial weight). In another study [39], weight loss, even when associated to a decreased strength, was associated with significant improvements in postural stability (decreased range and speed of the CoP). This result does not support the suggestion that strength is a key factor for improving balance control since a decrease in strength lead to an increased stability. Several recent studies with different age groups also show that little correlation exists between strength and postural stability $[40,41]$ and that strength (resistance) training programs allow for an increase in strength, but have little beneficial effect on the improvement of postural stability [42]. In order to dissociate further the effect of training from that of weight on balance control, we evaluated young active adults having a BMI corresponding to the definition of an obese person (American football players with an average BMI of $35.3 \mathrm{~kg} / \mathrm{m}^{2}$ ) and having above average lower limb strength [17•]. Balance control of these participants was compared to that of sedentary obese people (average BMI of $34.0 \mathrm{~kg} / \mathrm{m}^{2}$ ) and that of people having a healthy weight (average BMI of $22.5 \mathrm{~kg} / \mathrm{m}^{2}$ ). Remarkably, active obese participants oscillated as much as sedentary obese people and these two groups showed greater speed and range of 
the CoP than participants having a healthy weight (mean CoP speed of $0.83 \mathrm{~cm} / \mathrm{s}, 0.87 \mathrm{~cm} / \mathrm{s}$ and $0.60 \mathrm{~cm} / \mathrm{s}$, respectively for the active and sedentary obese and for the participants with a healthy weight with vision). These results were observed despite the fact that the lower limb strength of active obese participants (American football players) was nearly twice as large as that of obese participants (1593 N vs. $796 \mathrm{~N}$ for the maximal force of the quadriceps). At the time of the experiment, young active obese participants took part in six sessions of training (i.e., strength and cardiovascular) per week while participants of the two other groups were sedentary. Overall, this work suggests that neither a non-specific muscular training, nor an important muscular strength of the lower limbs improves the postural stability of obese individuals. Rather, the weight of a person (and weight loss) is a crucial determinant of balance control.

A limitation of the above work is that quasi-static conditions were examined. One may argue that greater strength could allow overcoming small perturbations or balance recoveries following tripping events. Recent work by Matrangola and Madigan [43] provides an initial response to this important question. In their study, obese subjects were unable to recover balance using an ankle strategy as well as normal weight individuals when perturbations involved an initial angular velocity. However, no differences between obese and normal weight individuals were found when perturbations only involved an initial angular displacement. The authors suggested a possible beneficial effect of increased inertia on balance recovery after perturbations only for conditions with little or no initial angular velocity. This important effect of the initial conditions also was suggested by Corbeil et al. [32]. In particular, these authors mentioned that any delay in the onset of a corrective response (which automatically leads to an increased angular velocity) results in a need for a greater torque to stabilize the body. Another study investigated the relationship between obesity and falls (in middle-aged and older women) in both the community setting as well as the laboratory [44]. No difference was found in the rate of falls in the community between healthy and obese middle-aged and older women, but during the laboratory based induced trips there was an increase in the rate of falls ( $46 \%$ vs. $25 \%$ ) for the obese compared to the healthy weight individuals. These authors suggested that the difference in the rate of falls for induced trips could be related to an altered recovery response in obese individuals.

\section{Obesity may Alter the Sensory Message Arising from the Plantar Mechanoreceptors}

The work of Roll and his collaborators [e.g., 45] suggests an important contribution of the plantar mechanoreceptors for controlling human balance through the detection of the body position with respect to the vertical reference. Plantar sole pressures vary with body weight. Despite the fact that obese individuals have larger footprints, Gravante et al. [46] observed that, when standing, the pressure peaks were 40 to $45 \%$ higher among obese individuals compared to individuals having a normal weight. Furthermore, Hills et al. [47] demonstrated, by comparing eight anatomical regions under the feet of obese people and normal-weight people, that all the plantar pressures were higher in obese people. There is a possibility that these higher plantar pressures could decrease the sensitivity of the plantar mechanoreceptors. According to Weber's law, the magnitude of a stimulus (psychophysics differential threshold, $\Delta \mathrm{I}$ ) is determined by the just-noticeable difference between two stimuli [48]. The differential threshold would be directly proportional to the initial intensity of the stimulus (I) and a constant (Weber fraction, $\mathrm{k}$ ) that depends on the sensory system $(\Delta \mathrm{I}=\mathrm{k} \cdot \mathrm{I})$. In other words, the capacity to perceive a difference in the signal occurs only when an increase of the stimulus exceeds a constant percentage of the initial intensity of the stimulus. Bensmaïa et al. [49] have demonstrated this relationship by showing that the distinction of the mechanoreceptors could be affected by a constant stimulus on the volar region of the hand in monkeys. To our knowledge, this demonstration has not yet been made at the level of plantar mechanoreceptors. According to Weber's law, overweight people (because of a greater stimulation of their plantar mechanoreceptors compared to a healthy-weight person) would have a higher differential threshold than individuals having a healthy weight. This would entail that the capacity to perceive changes in the position of the $\mathrm{CoP}$ is less efficient in obese people than in healthy-weight individuals. By retaking in a simplistic manner the data of Gravante et al. [46], we might speculate that the differential threshold of obese individuals would be 40 to $45 \%$ higher than that of healthy-weight individuals. This reduced perceptual sensitivity could, at least in part, explain the increased CoP speed and displacements characterizing balance control of overweight individuals $[6,12,14,15,50,51]$. Increased inflammatory responses related to obesity may also affect the sensitivity of the neural receptors in the foot [52]. Weight loss could therefore allow regaining differential threshold values comparable to those of healthy weight individuals and thus explain the improved balance control observed in Teasdale et al. [6].

To test this hypothesis, we recently examined whether an added mass decreases plantar sole sensitivity when standing upright [53]. Ten male subjects with a healthy weight (height $178 \pm 5 \mathrm{~cm}$, weight $78.3 \pm 8.2 \mathrm{~kg}$, BMI $24.7 \pm 2.2 \mathrm{~kg} / \mathrm{m}^{2}$, age $23.9 \pm 3.8$ years) stood on a custom-designed platform without or with a loaded vest that increased their weight by $23 \mathrm{~kg}$. Heel plantar sole sensitivity was determined in weight bearing conditions with and without the loaded vest via a psychophysical approach (method of limits - reverse staircase approach). The platform $(70 \mathrm{~cm} \times 100 \mathrm{~cm})$ was elevated from the floor, and a portion of the standing surface was perforated with $0.15 \mathrm{~cm}$ holes, spaced $2 \mathrm{~cm}$ apart. The holes were pierced so that a small 
aluminum probe (tip diameter $=0.1 \mathrm{~cm}$ ) could pass through and come into contact with the foot sole. The probe was controlled from beneath the platform through a linear actuator moving at a constant velocity of $8.25 \mathrm{~mm} / \mathrm{s}$. A load cell was placed in series with the actuator and probe to measure the force applied against the plantar sole. Participants were instructed to look at the realtime displacement of their CoP that was displayed on a screen located at eye-level $70 \mathrm{~cm}$ in front of them. Specific CoP target positions (neutral, forward leaning, backward leaning) were presented in order to load/unload the heels. Changes in the amplitude of the probe created changes in the force applied to the heel of the plantar sole. In fixed increments $(0.05 \mathrm{~mm})$ the probe amplitude increased (or decreased) as the subjects responded 'yes' or 'no' respectively, based on their perception of foot sole to probe contact. When a reversal of responses occurred, for example, repeated 'yes' responses became a 'no' (or vice versa), the direction of the probe (ascending or descending) changed. The mean sensitivity was determined by averaging the force values at each of the reversals for each condition (loaded/unloaded for the three body postures). The key result of this study is that plantar sole sensitivity decreased when participants wore the loading vest in the neutral and backward posture (that is when heel receptors were loaded), suggesting that an added mass during upright standing reduces plantar sole sensitivity. When unloaded, a $20 \mathrm{~g}$ pressure was sufficient to detect a probe contact whereas more than $30 \mathrm{~g}$ was necessary when subjects wore the loaded vest (an increased threshold of $30 \%$ when loaded). Obviously, this result needs to be confirmed with obese individuals, but it clearly suggests that obese individuals may suffer from a reduced plantar sole sensitivity. Consequently, weight loss likely improves balance control by unloading the plantar sole leading to better detection of CoP oscillations.

\section{Conclusion}

The importance of obesity as a factor in the prediction and especially in the prevention of falls has received little attention. Obese individuals are less stable than healthy-weight individuals and this decreased stability reduces the performance of upper-limb movements. Without weight loss, it seems that neither an active lifestyle including a regular physical activity program, nor greater strength allows for the mitigation of these negative effects of excess mass on balance control [17•]. It may be that, for obese persons, a combination of both increased mechanical constraints and reduced sensation from the plantar mechanoreceptors translates in balance control impairments.

Acknowledgments We would like to thank Dr. Darja Rugelj for helpful comments on a previous version of this manuscript.

\section{Compliance with Ethics Guidelines}

Conflict of Interest Normand Teasdale declares that he has no conflict of interest.

Martin Simoneau declares that he has no conflict of interest. Philippe Corbeil declares that he has no conflict of interest. Grant Handrigan declares that he has no conflict of interest. Angelo Tremblay declares that he has no conflict of interest. Olivier Hue declares that he has no conflict of interest.

Human and Animal Rights and Informed Consent This article does not contain any studies with human or animal subjects performed by any of the authors.

\section{References}

Papers of particular interest, published recently, have been highlighted as:

- Of importance

1. Finkelstein EA, Chen H, Prabhu M, Trogdon JG, Corso PS. The relationship between obesity and injuries among U.S. adults. Am J Health Promot. 2007;21(5):460-8.

2. Matter KC, Sinclair SA, Hostetler SG, Xiang H. A comparison of the characteristics of injuries between obese and non-obese inpatients. Obesity. 2007;15(10):2384-90.

3. Pollack KM, Cheskin LJ. Obesity and workplace traumatic injury: does the science support the link? Inj Prev. 2007;13(5):297-302.

4. Janssen I, Bacon E, Pickett W. Obesity and its relationship with occupational injury in the canadian workforce. J Obes [Internet]. 2011 [cited 2012 Jun 21];2011.

5. Lemon SC, Zapka J, Li W, Estabrook B, Rosal M, Magner R, et al. Step ahead: a worksite obesity prevention trial among hospital employees. Am J Prev Med. 2010;38(1):27.

6. Teasdale N, Hue O, Marcotte J, Berrigan F, Simoneau M, Dore J, et al. Reducing weight increases postural stability in obese and morbid obese men. Int J Obes (Lond). 2007;31(1):153-60.

7. Berrigan F, Simoneau M, Tremblay A, Hue O, Teasdale N. Influence of obesity on accurate and rapid arm movement performed from a standing posture. Int J Obes (Lond). 2006;30(12):1750-7.

8. D'Hondt E, Deforche B, De Bourdeaudhuij I, Lenoir M. Childhood obesity affects fine motor skill performance under different postural constraints. Neurosci Lett. 2008;440(1):72-5.

9. Geurts ACH, Nienhuis B, Mulder TW. Intrasubject variability of selected force-platform parameters in the quantification of postural control. Arch Phys Med Rehabil. 1993;74(11):1144-50.

10. Maki BE, Holliday PJ, Fernie GR. Aging and postural control. A comparison of spontaneous- and induced-sway balance tests. J Am Geriatr Soc. 1990;38(1):1-9.

11. Teasdale N, Stelmach GE, Breunig A, Meeuwsen H. Age differences in visual sensory integration. Exp Brain Res. 1991;85:691-6.

12. Hue O, Simoneau M, Marcotte J, Berrigan F, Doré J, Marceau P, et al. Body weight is a strong predictor of postural stability. Gait Posture. 2007;26(1):32-8.

13. D'Hondt E, Deforche B, De Bourdeaudhuij I, Gentier I, Tanghe A, Shultz S, et al. Postural balance under normal and altered sensory conditions in normal-weight and overweight children. Clin Biomech (Bristol, Avon). 2011;26(1):84-9. 
14. Goulding A, Jones IE, Taylor RW, Piggot JM, Taylor D. Dynamic and static tests of balance and postural sway in boys: effects of previous wrist bone fractures and high adiposity. Gait Posture. 2003;17(2):136-41.

15. McGraw B, McClenaghan BA, Williams HG, Dickerson J, Ward DS. Gait and postural stability in obese and nonobese prepubertal boys. Arch Phys Med Rehabil. 2000;81(4):484-9.

16. Bauer LO, Wu Z, Wolfson LI. An obese body mass increases the adverse effects of HIV/AIDS on balance and gait. Phys Ther. 2011;91(7):1063-71.

17. • Handrigan GA, Berrigan F, Hue O, Simoneau M, Corbeil P, Tremblay A, et al. The effects of muscle strength on center of pressure-based measures of postural sway in obese and heavy athletic individuals. Gait Posture. 2012;35(1):88-91. A group of heavy but athletic individuals was compared to sedentary obese and healthy weight individuals for testing the hypothesis that strength and training could improve balance control. Despite being much stronger, individuals in the athletic group swayed similarly to the obese, that is more than individuals with a healthy weight. This suggests that muscular strength has a minimal relationship with postural sway in obese and heavy athletic individuals during normal quiet standing.

18. Cimolin V, Galli M, Rigoldi C, Grugni G, Vismara L, Mainardi L, et al. Fractal dimension approach in postural control of subjects with Prader-Willi Syndrome. J Neuroeng Rehabil. 2011;8:45.

19. Dutil M, Handrigan GA, Corbeil P, Cantin V, Simoneau M, Teasdale N, et al. The impact of obesity on balance control in community-dwelling older women. Age (Dordrecht, Netherlands) [Internet]. 2012 [cited 2012 Feb 21];

20. Błaszczyk JW, Cieślinska-Swider J, Plewa M, ZahorskaMarkiewicz B, Markiewicz A. Effects of excessive body weight on postural control. J Biomech. 2009;42(9):1295-300.

21. Handrigan GA, Corbeil P, Simoneau M, Teasdale N. Balance control is altered in obese individuals. J Biomech. 2010;43(2):383-4. author reply $385-386$.

22. Bouisset S, Lestienne F. The organisation of a simple voluntary movement as analysed from its kinematic properties. Brain Res. 1974;71:451-7.

23. Lee W. Anticipatory control of postural and task muscles during rapid arm flexion. J Mot Behav. 1980;12:185-96.

24. Mallau S, Simoneau M. Aging reduces the ability to change grip force and balance control simultaneously. Neurosci Lett. 2009;452(1):23-7.

25. Massion J. Postural changes accompanying voluntary movements. Normal and pathological aspects. Hum Neurobiol. 1984;2:261-7.

26. Nashner LM, Cordo PJ. Relation of automatic postural responses and reaction-time voluntary movements of human leg muscles. Exp Brain Res. 1981;43:395-405.

27. Berrigan F, Simoneau M, Martin O, Teasdale N. Coordination between posture and movement: interaction between postural and accuracy constraints. Exp Brain Res. 2006;170(2):255-64.

28. Fitts PM. Cognitive aspects of information processing: 11l, set for speed versus accuracy. J Exp Psychol Learn Mem Cogn. 1966;71(6):849-57.

29. Berrigan F, Hue O, Teasdale N, Simoneau M. Obesity adds constraint on balance control and movement performance. Hum Factors Ergon Soc Ann Meet Proc. 2008;52:1364-8.

30. D'Hondt E, Deforche B, Gentier I, De Bourdeaudhuij I, Vaeyens R, Philippaerts R, et al. A longitudinal analysis of gross motor coordination in overweight and obese children versus normal-weight peers. Int J Obes (Lond) [Internet]. 2012 [cited 2012 Jun 20 in-press].

31. Li X, Aruin AS. The effect of short-term changes in the body mass on anticipatory postural adjustments. Exp Brain Res. 2007;181(2):333-46.

32. Corbeil P, Simoneau M, Rancourt D, Tremblay A, Teasdale N. Increased risk for falling associated with obesity: mathematical modeling of postural control. IEEE Trans Neural Syst Rehabil Eng. 2001;9(2):126-36.
33. Capodaglio P, Menegoni F, Vismara L, Cimolin V, Grugni G, Galli M. Characterisation of balance capacity in Prader-Willi patients. Res Dev Disabil. 2011;32(1):81-6.

34. Maffiuletti NA, Agosti F, Proietti M, Riva D, Resnik M, Lafortuna $\mathrm{CL}$, et al. Postural instability of extremely obese individuals improves after a body weight reduction program entailing specific balance training. J Endocrinol Invest. 2005;28(1):2-7.

35. Sartorio A, Lafortuna CL, Conte G, Faglia G, Narici MV. Changes in motor control and muscle performance after a short-term body mass reduction program in obese subjects. $\mathrm{J}$ Endocrinol Invest. 2001;24(6):393-8.

36. Levine JA, Lanningham-Foster LM, McCrady SK, Krizan AC, Olson $\mathrm{LR}$, Kane $\mathrm{PH}$, et al. Interindividual variation in posture allocation: possible role in human obesity. Science. 2005;307(5709):584-6.

37. Capodaglio P, Cimolin V, Tacchini E, Parisio C, Galli M. Balance control and balance recovery in obesity. Curr Obes Rep. 2012;1(3):166-73.

38. Hue O, Berrigan F, Marcotte J, Simoneau M, Marceau P, Marceau $\mathrm{S}$, et al. Muscle force and force control after a weight loss in obese and morbid obese men. Obes Surg. 2008;18(9):1112-8.

39. Handrigan G, Hue O, Simoneau M, Corbeil P, Marceau P, Marceau $\mathrm{S}$, et al. Weight loss and muscular strength affect static balance control. Int J Obes (Lond). 2010;34(5):936-42.

40. Granacher U, Gollhofer A. Is there an association between variables of postural control and strength in prepubertal children? J Strength Cond Res. 2012;26(1):210-6.

41. Muehlbauer T, Gollhofer A, Granacher U. Relationship between measures of balance and strength in middle-aged adults. J Strength Cond Res [Internet]. 2011 [cited 2012 Mar 22, in-press];

42. Granacher U, Gruber M, Gollhofer A. Resistance training and neuromuscular performance in seniors. Int J Sports Med. 2009;30(9):652-7.

43. Matrangola SL, Madigan ML. The effects of obesity on balance recovery using an ankle strategy. Hum Mov Sci. 2011;30(3):584-95.

44. Rosenblatt NJ, Grabiner MD. Relationship between obesity and falls by middle-aged and older women. Arch Phys Med Rehabil. 2012;93(4):718-22.

45. Kavounoudias A, Roll R, Roll JP. The plantar sole is a "dynamometric map" for human balance control. Neuroreport. 1998;9(14):324752.

46. Gravante G, Russo G, Pomara F, Ridola C. Comparison of ground reaction forces between obese and control young adults during quiet standing on a baropodometric platform. Clin Biomech (Bristol, Avon). 2003;18(8):780-2.

47. Hills AP, Hennig EM, McDonald M, Bar-Or O. Plantar pressure differences between obese and non-obese adults: a biomechanical analysis. Int J Obes. 2001;25(11):1674-9.

48. Lanzara RG. Weber's law modeled by the mathematical description of a beam balance. Math Biosci. 1994;122(1):89-94.

49. Bensmaia SJ, Leung YY, Hsiao SS, Johnson KO. Vibratory adaptation of cutaneous mechanoreceptive afferents. J Neurophysiol. 2005;94(5):3023-36.

50. Cruz-Gómez NS, Plascencia G, Villanueva-Padrón LA, JáureguiRenaud K. Influence of obesity and gender on the postural stability during upright stance. Obesity Facts. 2011;4(3):212-7.

51. Menegoni F, Galli M, Tacchini E, Vismara L, Cavigioli M, Capodaglio P. Gender-specific effect of obesity on balance. Obesity (Silver Spring). 2009;17(10):1951-6.

52. Miscio G, Guastamacchia G, Brunani A, Priano L, Baudo S, Mauro A. Obesity and peripheral neuropathy risk: a dangerous liaison. J Peripher Nerv Syst. 2005;10(4):354-8.

53. Handrigan G, Simoneau M, Teasdale N, Corbeil P. The sort-term effects of added mass on plantar sole sensitivity during upright standing. Trondheim: International Society for Posture and Gait Research; 2012. 